\title{
A new appraisal of Mental Health Review Tribunals
}

\author{
A. T. GRounds, University Lecturer in Forensic Psychiatry, Institute of Criminology and \\ Department of Psychiatry, 7 West Road, Cambridge
}

\begin{abstract}
Mental Health Review Tribunals were introduced in the Mental Health Act (1959) to safeguard psychiatric patients against unjustified detention in hospital. The powers of tribunals form "an important part of the fabric of civil liberties" (Wood, 1974). However, in exercising their prime function of preventing unjust detention, tribunals in practice also have to take into account patients' clinical needs and the protection of the public. Further weight was added to this complex burden of decision making following a judgement by the European Court of Human Rights in 1981 which upheld the right of all detained patients to a periodic judicial review of their detention. As a result of this judgement the Mental Health Act (1983) extended tribunal powers to include the release of offender patients sentenced by Crown courts and given hospital orders with restrictions on discharge. Such individuals may have been convicted of grave criminal offences, and their discharge or transfer from hospital would otherwise require the consent of the Home Office.
\end{abstract}

The specific statutory criteria for release vary according to the particular section of the Mental Health Act under which the patient is detained, but in general terms discharge must be ordered by a tribunal if either of two conditions are fulfilled: either the person no longer suffers from mental disorder of a nature or degree warranting detention for treatment in hospital; or, such treatment is no longer needed for the health or safety of the patient, or for the protection of others.

Previous research and commentaries have drawn attention to the administrative and operational difficulties faced by tribunals in translating their statutory duties into practice (Peay, 1984; Hepworth, 1985; Wood, 1985). A recently completed DHSS funded study of the workings of Mental Health Review Tribunals by Dr Jill Peay of the Centre for Criminological Research, Oxford, probes these issues further and her findings raise some fundamental questions about the functions of tribunals and about the legal framework of sentencing for mentally disordered offenders. An initial presentation and discussion of the research took place at a stimulating day conference chaired by Sir John Wood at St Catherine's College, Oxford, on 20 April 1988. Two talks by Dr Peay were interspersed with responses and commentaries by Dr Philip Bean (University of Nottingham), Mr William Bingley (MIND), Mrs
Elizabeth Parker (Special Hospitals Research Unit, DHSS) and Dr David Mawson (Moss Side Hospital). The DHSS sponsored conference exemplified a welcome interest in disseminating and generating informed debate about new research findings amongst those in the field.

Dr Peay's study of the operation of tribunals under the 1983 Mental Health Act was designed to evaluate the effects of the new provisions introduced in that legislation. The fieldwork involved interviews with patients in one special hospital, their Responsible Medical Officers (RMOs), and judicial members of the tribunal; observation of hearings in a range of hospitals in two tribunal regions, and examination of case files. A detailed analysis was made of two groups of 40 patients with "mental illness" and "psychopathic disorder" who were detained in special hospitals in two regions. This brief account cannot do justice to the range and depth of the study, but selects only one or two themes relating to mentally disordered offenders. A full account of Dr Peay's research will be available in a forthcoming book, Tribunals on Trial: Decision Making under the Mental Health Act 1983 to be published by Oxford University Press.

The research findings showed that tribunal decisions on restricted patients were cautious. Patients were almost never discharged unless this was recommended by the RMO; and, overall, the advice of RMOs (which was mainly that the patient should remain detained) was followed in more than $80 \%$ of the hearings. On the rare occasions when tribunal decisions conflicted with the RMOs recommendation, this was usually because the tribunal viewed the case more cautiously than the RMO, favouring detention for longer than the consultant considered necessary. The majority of judicial members regarded issues of public safety as their paramount consideration, and it was clear that in cases where there was doubtful evidence of mental disorder but concern about risk to others, the latter would generally take precedence and the patient would not be discharged. There was little evidence that tribunals' new legal powers to discharge restricted patients are, in practice, failing to protect public safety.

Precisely because the issue of risk to the public takes precedence in tribunal decision making, it is questionable whether tribunals are at the same time providing an adequate safeguard for individual 
patients. The validity of continued detention under the Mental Health Act depends on the continuation of the mental disorder: it is wrong in principle to detain under mental health legislation someone who is not mentally disordered, and a person who no longer has a disorder warranting detention has to be released. This was the principle at the heart of the European Court of Human Rights' judgement in 1981: it provides the justification for the tribunal's powers and states its substantive function. But can this function be properly exercised when considerations of public safety determine tribunal judgements? Dr Peay's work suggests that conflicts and uncertainties in medical evidence were used to justify detention because they prevented tribunals from being satisfied about the absence of mental disorder. Proposals for continuing treatment were inherently attractive, and tribunals were further constrained by their lack of power to enforce recommendations for transfer to less secure hospital environments and by a perceived lack of alternative facilities.

The Mental Health Act (1983) introduced not only new powers for tribunals but new procedures designed to ensure more openness, so that patients are usually able to receive copies of medical reports and to attend throughout the hearing. These changes were welcomed by the special hospital patients interviewed, who expressed concern about infrequent contact with their consultants, and reported applying for tribunal hearings in order to find out about their clinical progress. The improvements in procedural arrangements are important, but is it right to evaluate the effectiveness of tribunals in terms of patients thereby receiving regular clinical reviews, information, independent opinions and clear plans for their future treatment and after-care? These should be matters of normal, good clinical practice.

Some of the difficulties faced by tribunals arise from the potential conflicts in their statutory duties. In reaching a decision in the case of an individual who has been sentenced for a grave offence, how could a conscientious tribunal entirely set aside the issue of public safety and consider discharge on the "mental disorder" criterion alone? The task strictly enshrined in the legislation is not a reasonable one, and which of us would act any less cautiously if faced with the tribunal's dilemma? Nevertheless, tribunals could still do much more to consider rigorously the specific question of whether there is mental disorder warranting detention: it should not be a secondary issue used only to rationalise a decision to detain or release on grounds of perceived dangerousness. Further study in this area, for example, comparing tribunal decision making with clinical and diagnostic practice in other contexts is needed.

As Dr Peay perceives, behind the tribunal's dilemma lies the framework of specific sentencing for mentally disordered offenders, which is based on the principles of enabling indeterminate detention for the dual purposes of treatment and public protection. Not only may these objectives conflict, but when they are the sole aims of sentencing, and periods of detention are not limited by consideration of 'tariff' there is potential for injustice. But should considerations of tariff apply to the mentally disordered, and would those responsible for the care of such offenders accept yet another non-clinical determinant of detention in hospital?

Dr Peay's research will require thorough and thoughtful debate, not only because of the many specific suggestions it contains for enhancing the work and practice of tribunals, but because it highlights complex and important issues concerning the law and provision of services for mentally disordered offenders.

\section{Acknowledgements}

I am grateful to Dr Jill Peay and to Dr Mary Dastgir for comments on the manuscript.

\section{References}

HePworth, D. (1985) Dangerousness and the Mental Health Review Tribunal. In Aggression and Dangerousness (eds. D. P. Farrington \& J. Gunn). Chichester: John Wiley.

Peay, J. (1984) Mental Health Review Tribunals and the Mental Health (Amendment) Act. Criminal Law Review, 794-808.

WoOD, J. C. (1974) Mental Health Review Tribunals: a reappraisal. Medicine, Science and the Law, 16, 212-218.

- (1985) Detention of patients: administrative problems facing Mental Health Review Tribunals. In Psychiatry. Human Rights and the Law (eds. M. Roth \& R. Bluglass). Cambridge: Cambridge University Press.

$X$ v. United Kingdom Application No 6998/75 European Court of Human Rights, judgement given 5 November 1981. Council of Europe, Strasbourg. 